\title{
Erratum to: Nature-Based Tourism in Turkey: The Yayla in Turkey's Eastern Black Sea Region
}

\author{
Faruk Alaeddinoğlu and Mehmet Șeremet
}

\section{Erratum to:}

Chapter 5 in: I. Egresi (ed.), Alternative Tourism in Turkey, GeoJournal Library 121,

DOI 10.1007/978-3-319-47537-0_5

In the original version of the book, acknowledgement has to be newly included in Chapter 5. The erratum chapter and the book have been updated with the change. 